\title{
O tempo e a forma: a configuração de núcle- os urbanos a partir da transformação do par- celamento agrícola. Estudo de caso: Colônia de Caxias/RS
}

Time and form: the configuration of urban nuclei from the transformation

of agricultural parceling. Case study: Colônia de Caxias/RS

Dirceu Piccinato Junior*, Kátia Savaris Dametto**

*Doutor em Urbanismo e Docente do Programa de PósGraduação Stricto sensu em Arquitetura e Urbanismo da Faculdade Meridional IMED. ORCID: 0000-00015153-0931
**Mestre em Arquitetura e Urbanismo pela Faculdade Meridional - IMED. ORCID: 0000-0002-6369-6848

\section{Resumo}

O presente artigo tem o objetivo de analisar o processo de transformação do parcelamento agrícola em urbano da Colônia de Caxias/RS. Tendo em vista a necessidade de povoar as extensas áreas de terras disponíveis no século XIX, houve a criação de imperiosas políticas governamentais que facilitaram o acesso da população estrangeira ao Rio Grande do Sul. A Lei de Terras de 1850 , ou Lei $n^{\circ} 601$ de 18 de setembro de 1850 , dispunha de regulamentações que normatizavam o modo de inserção do colono em terras nacionais, a distribuição de terras públicas e a transformação da terra em mercadoria. A metodologia adotada para este trabalho estrutura-se no levantamento e análises de fontes documentais primárias, como mapas, decretos e relatórios de época. Conjuntamente à sistematização desses dados destaca-se a bibliografia pertinente a temática. $\mathrm{O}$ artigo é de caráter exploratório e qualitativo. Além do objetivo geral supracitado, destacam-se como objetivos específicos: compreender o processo, mapear o parcelamento e o saber erudito do responsável pelo traçado urbano. Como resultado alcançado, pondera-se que a ortogonalidade empregada na sede de Caxias tinha como objetivo central facilitar o comércio dos lotes, rurais e urbanos.

Palavras-chave: Forma urbana. Colônias agrícolas. Parcelamento da terra.

\section{Abstract}

This article aims to analyze the process of transforming agricultural to urban subdivision in Colônia de Caxias / RS. In view of the need to populate the extensive areas of land available in the 19th century, imperative government policies were created that facilitated the access of the foreign population to Rio Grande do Sul. The Land Law of 1850, or Law No. 601 of 18 from September 1850, it had regulations that regulated the colonist's insertion in national lands, the distribution of public lands and the transformation of the land into merchandise. The methodology adopted for this work is based on the survey and analysis of primary documentary sources, such as maps, decrees and period reports. Together with the systematization of these data, the relevant bibliography on the subject stands out. The article is exploratory and qualitative. In addition to the aforementioned general objective, the following stand out as specific objectives: to understand the process, map the parceling and the erudite knowledge of the person responsible for the urban layout. As a result achieved, it is considered that the orthogonality employed at the headquarters of Caxias had as its central objective to facilitate the trade of plots, rural and urban.

Keywords: Urban form. Agricultural colonies. Land parceling. 


\section{Introdução}

A expressão forma urbana pode apontar diferentes conotações conceituais. Todavia, para o presente artigo, o termo adere ao conceito de espaço urbano, pois esse é igualmente definido por seus limites. Assim, qualquer espaço em que nos encontremos é fisicamente delimitado, a ponto de estruturarmos sua noção a partir da compreensão das relações topológicas e perspectivas entre nosso corpo e as superfícies que realizam a demarcação do espaço em que nos inserimos. Essa breve consideração denota que a característica morfológica é o principal identificador dos espaços socialmente utilizados. Nesse sentido, falar em forma dos espaços urbanos é remeter à abordagem dos processos de organização social na cidade a partir de seus aspectos configurativos (HOLANDA et al, 2000).

O território que hoje conforma o atual estado do Rio Grande do Sul, no século XVIII, era constituído por terras até então desocupadas, de posse de portugueses e espanhóis. Sendo assim, o referido território estruturou-se por meio de movimentos imigratórios no decorrer do tempo - esses movimentos podem ser entendidos como estruturadores e modificadores do espaço. Diante desse fluxo imigratório a colonização do estado ocorreu em razão da chegada de diferentes povos, especialmente os europeus, que foram de fundamental importância para a construção desta paragem (BRUM NETO, 2012).

Para Röhnelt (2012), a partir da necessidade de povoar as terras do Rio Grande do Sul, sob as perspectivas de incentivos e políticas, houve a necessidade de uma reorganização fundiária. As colônias foram sendo estabelecidas e como consequência a forma rural e urbana foi ganhando contornos.

As colônias foram sendo implantadas de modo precário e, de certa forma, sem muitos cuidados com os aspectos geográficos e sociais já que os imigrantes esgotavam suas finanças antes mesmo de adquirirem os lotes prometidos, acarretando a necessidade da busca por serviços externos como a aber- 
tura de estradas e picadas. Os núcleos urbanos, no início do século XIX, eram implantados a grandes distâncias uns dos outros, resultando em uma estagnação da economia. Ainda nesse momento os colonos passavam por dificuldades na produção e comercialização de produtos (RÖHNELT, 2012).

Para tanto, a colonização é um modo particular de povoamento de um território. Ao fundar colônias de imigrantes estrangeiros, o governo imperial financiou e administrou os serviços de transporte, demarcação de terras e estabelecimento dos imigrantes. Os objetivos eram acelerar o desenvolvimento da agricultura e povoar a região. As colônias fundadas pelo governo tinham suas áreas demarcadas $e$ subdivididas em lotes que eram vendidos aos imigrantes. Esses últimos tinham a obrigação de ocupar o lote e cultivá-lo, contando com um prazo de cinco anos para pagá-lo ao governo. Não apenas os lotes rurais foram demarcados durante a colonização, mas também a sede da colônia, ou seja, sua área urbana (STORMOWSKI, 2005). Um exemplo desse processo é a ex-colônia de Caxias e sua sede, a atual cidade de Caxias do Sul.

A metodologia utilizada neste artigo é adotada a partir da interlocução entre as bibliografias específicas e as referências no âmbito da colonização e da urbanização da Província de São Pedro e da Colônia de Caxias e fontes documentais primárias. Essas últimas foram coletadas no Arquivo Histórico Municipal João Spadari Adami localizado na cida- de Caxias do Sul, como mapas, memoriais de lotes, entre outros arquivos que permitiram a interpretação dos fatos.

Levando em consideração o contexto historiográfico da época, isto é, a partir da promulgação da Lei de Terras de 1850 e, tendo em vista a necessidade do governo imperial em povoar novas terras, o presente trabalho tem como objetivo principal analisar a forma urbana da sede da ex-colônia de Caxias.

\section{A política de imigração e a Lei de Terras de 1850}

O início da imigração para o Rio Grande do Sul não pode ser desvinculado da preocupação do Império brasileiro com a defesa da região sul. O Sul foi historicamente uma região do Império em certa medida militarizada, por fazer fronteira com as ex-colônias espanholas, os atuais Estados nacionais da Argentina e do Uruguai, de modo que a imigração tinha em vista a defesa da fronteira. Além disso, era objetivo do governo nacional desenvolver a agricultura em pequena propriedade nessa região a fim de alcançar a autossuficiência na produção de grãos e também incrementar as exportações (STORMOWSKI, 2005).

Segundo a pesquisadora Marcia Sanocki Stormowski (2005), a imigração oficial no século XIX iniciou com a chegada de imigrantes alemães à Colônia de São Leopoldo em 1824 (Figura 1). Até a Lei 


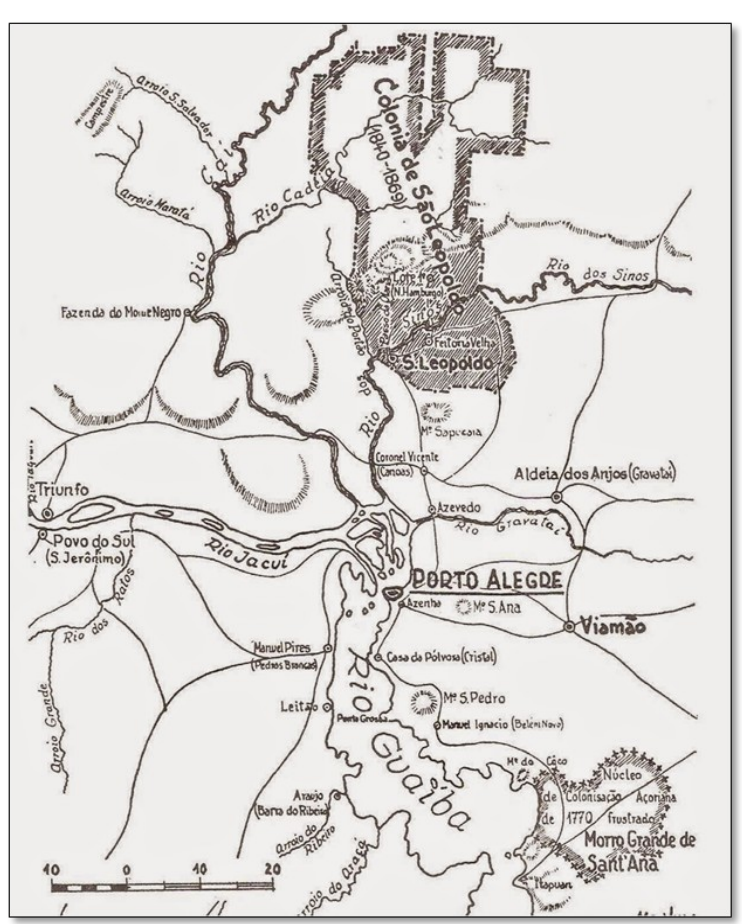

Figura 1. Mapa da localização da colônia de São Leopoldo em 1897. Fonte: Diretoria de Obras Públicas, Terras e Colonização de Porto Alegre.
Terras de 1850 os imigrantes receberam lotes gratuitamente de cerca de 70 até 100 hectares, juntamente receberam assistência no fornecimento de alimentos, sementes e ferramentas. Outras nações participaram do povoamento do Sul, entre eles os russos, os poloneses e os austríacos. Mas até a década de 1870 o maior contingente de imigrantes era formado de alemães.

A política de colonização a partir da segunda metade do século XIX baseou-se em uma legislação precisa, que forneceu diretrizes seguras para que fosse possível obter metas viáveis. A principal política de regulação territorial que assegurou a forma de distribuição de terras foi a Lei $n^{\circ} 601$ de 18 de setembro de 1850, conhecida popularmente como Lei de Terras de 1850 (GIRON, 1977).

Ao abordarmos a Lei de Terras de 1850, é possível compreender a sua representatividade e a fundamental importância para o século XIX, tendo em vista que foi uma mudança significativa para o Brasil, principalmente no âmbito rural. A expansão europeia e as diversas revoluções como a Revolução Industrial, a Revolução Francesa, entre outras, influenciaram o meio rural por intermédio da propriedade fundiária. A Lei de Terras pode ser interpretada como um instrumento legislativo que tinha como objetivo o ordenamento da terra (GASSEN, 1994).
A Lei $n^{\circ} 601$ de 18 de setembro de 1850 ou a comumente Lei de Terras de 1850, dispõe sobre as devolutas do Brasil na época do Império. Ela é composta de dezoito artigos e vários incisos sobre as terras que foram possuídas por título de sesmaria sem preenchimento das condições legais, bem como pelo simples título de posse mansa e pacífica. Essa lei determinou que, uma vez medidas e demarcadas as primeiras sesmarias, elas seriam cedidas a título oneroso, tanto para empresas, como para o estabelecimento de colônias nacionais e estrangeiras, autorizando o Governo Imperial brasileiro a promover a colonização estrangeira na forma que se declara na referida legislação. Essa legislação estabeleceu normas e cuidados com a terra rural, todavia, ela abriu inflexão para a formação dos espaços urbanos (PICCINATO JUNIOR, 2017).

A transformação da terra em mercadoria somente foi possível graças à referida lei. A legislação foi considerada a primeira lei agrária "nacional" com uma significativa importância para a apropriação de terras. Objetivava disciplinar a maneira de apropriação territorial e servir para parâmetros de medições, discriminações e venda das terras devolutas. Um pouco antes de 1850 já havia uma preocupação com relação à ocupação do território. Porém, somente em 1840 que os projetos que visavam à discussão da apropriação territorial resultariam na Lei de Terras (MOTTA, 1998). 
Segundo Faoro (2012) foi graças a essa legislação que houve uma separação da propriedade particular da terra devoluta. A propriedade particular dispunha de um registro paroquial, além de um título que garantisse ao senhor da terra seus direitos em defesa de um posseiro interessado em usucapião. Fixaram-se medidas administrativas com relação às demarcações efetuadas somente pelo poder público. Além do mais, a legislação dispunha de interesses com relação ao estímulo à colonização, isto é, o imigrante teria a terra para o cultivo, pagando-a em parcelas e atribuindo ao estado um povoamento produtivo (FAORO, 2012).

A destacada lei tinha ainda outra perspectiva, a transição do trabalho escravo para o trabalho livre e, na visão do governo imperial, a solução para que essa transição se operasse sem grandes problemas era a imigração estrangeira, que por sua vez precisava ser financiada. Para Ligia Osorio Silva (2008) uma forma de financiar esse processo seria a venda das terras devolutas da Coroa.

Silva (2008) complementa ainda que, em relação à imigração, a lei determinava que os estrangeiros que comprassem terras e nelas se estabelecessem seriam naturalizados, se quisessem, depois de dois anos residindo no Brasil, ficariam isentos de serviço militar, mas não do serviço da Guarda Nacional do município. A lei também autorizava o governo a mandar vir anualmente, à custa do tesouro, um certo número de colonos livres para se- rem empregados pelo tempo que fosse acordado em estabelecimentos agrícolas, nos trabalhos dirigidos pela administração pública ou na formação de colônias nos lugares que mais conviessem, tomando antecipadamente as medidas necessárias para que tais colonos achassem emprego assim que desembarcassem no país.

Para tanto, a Lei de Terras de 1850 amparava de forma significativa o desenvolvimento do latifúndio, além do que favorecia uma exploração das terras por meio de cobranças decorrentes da realização de medições e delimitações de regiões, além da cobrança de registros de propriedade. Foi de certa forma uma legislação que impôs limites ao direito do posseiro a adquirir novas terras e reconhecer propriedades públicas como sendo de seu pertencimento.

\section{Conformação do território sul rio-grandense}

Discutir a formação territorial é entender a sociedade num dado espaço. Toda sociedade para se reproduzir cria formas, mais ou menos duráveis, na superfície terrestre, daí sua condição de processo. Essas formas que obedecem a um dado ordenamento sociopolítico do grupo que as constrói, que respondem funcionalmente a uma sociabilidade vigente a qual regula também o uso do espaço e dos recursos nele contidos, definindo os seus modos próprios de apropriação da natureza (MORAES, 2005). 
1. Invernada é um local de pasto extenso, destinado a criação de gado e/ou outros animais. Geralmente, delimitado por barreiras artificiais.
Para que essas formas aconteçam é necessário um lugar, um espaço. A valorização do espaço pode, portanto, ser apreendida como processo historicamente identificado de formação de um território.

Pessoas, movimentos, estruturação, ocupação, construções e destruições passam a fazer parte desse espaço, qualificando-o para as apropriações futuras. Segundo Antonio Carlos Robert Moraes (2005) a constituição de um território é, assim, um processo cumulativo, a cada momento um resultado e uma possibilidade - um contínuo em movimento. Um modo parcial de ler a história.

O território é, concomitantemente, uma construção militar (um resultado da conquista espacial, que tem de ser reiterada sempre que contestada) e uma construção política (como área de exercício de um poder soberano), mas também uma construção econômica (como suporte de estruturas e diferentes atividades produtivas como um mercado e uma construção jurídica (que tem de ser legitimada em fóruns adequados de relacionamento internacional), e ainda uma construção ideológica (que fundamenta uma identidade social de base espacial) (MORAES, 2005).

Quando associamos a conformação territorial ao processo de colonização está-se implicando na criação de novas estruturas. Essas novas estruturas devem responder funcionalmente a interesses, isto é, o empreendimento deve gerar retorno econômico do investimento que representa.

Os primeiros habitantes chegaram às terras do atual estado do Rio Grande do Sul em meados de 1684 e foram denominados lagunistas pelo fato de que, com a abertura da Estrada dos Conventos, houve aumento no fluxo de gado. Esse fato fez com que os habitantes abandonassem a localidade de Laguna, situada no extremo sul do atual estado de Santa Catarina e procurassem novas terras. Francisco de Britto Peixoto, fundador e capitão-mor da vila de Laguna, realizou em 1690 inúmeras excursões para fazer o reconhecimento do caminho do Sul até a Colônia de Sacramento e explorar as jazidas de metais preciosos. Ordenou ao explorador João de Magalhães ocupar, em 1725, o litoral entre Tramandaí e o canal do Rio Grande. Esse fato marcou o início do povoamento, permitiu a instalação de invernadas ${ }^{1} \mathrm{e}$ facilitou o acesso dos lagunistas às terras em busca de condições favoráveis de vida (ROCHE, 1969).

A consolidação do território do Rio Grande do Sul aconteceu entre o fim do século XVIII e início do século XIX, em razão da economia pecuarista que passou a deter importância e com a colonização açoriana, concentrada mais na parte sul. Mediante essa primeira configuração territorial, observou-se a necessidade de colonizar a parte norte do estado. Os movimentos de ocupação territorial eram organizados a partir de políticas públicas, parcelamentos 


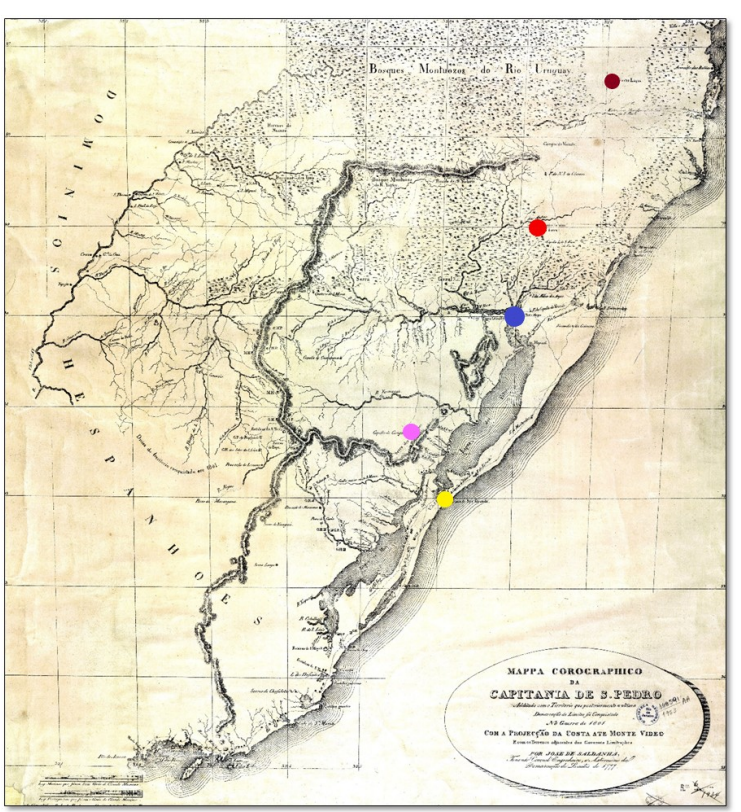

Figura 2. Mapa da Capitania de São Pedro, 1801. Destacam-se algumas vilas já formadas, como por exemplo, a Vila de Porto Alegre destacada em azul, a Vila de Lajes destacada em bordô, a Vila de São Pedro destacada em amarelo, a Serra de Tapes destacada em rosa, os Campos de cima da serra destacado em vermelho. Fonte: Instituto Histórico e Geográfico de Porto Alegre (adaptado pelos autores). de terras e incentivos econômicos. $E$ foi por meio de incentivos econômicos que o governo organizou a colonização no território, sendo essa chamada de "colonização dirigida". (ROCHE, 1969). Todavia, para Pesavento (2014), de 1780 a 1801 desenvolveu-se uma nova política de terras sob o governo Veiga Cabral, onde os açorianos foram retirados de suas terras para o beneficiamento dos pecuaristas.

Não há dúvida de que uma das primeiras construções para se consolidar um território são os núcleos urbanos. Para Nascimento (2009) as povoações criadas no território do Rio Grande do Sul foram originárias de localidades com determinadas funções. Elas nasceram em locais onde havia acampamentos militares; onde proprietários de sesmarias tinham estabelecido capelas; onde o governo ou particulares criaram colônias; ou onde anteriormente estavam as reduções ou aldeamentos guaranis (Figura 2). Em todas persistiu uma forma particular, isto é, a forma da cidade de origem portuguesa.

Quanto à forma urbana dessas cidades fundadas no Brasil a partir de preceitos portugueses, se caracteriza por diferentes aspectos: suas heranças culturais, as lógicas de localização e de escolha dos sítios para a implantação dos núcleos urbanos, os elementos geradores dos traçados, suas relação com as características físicas do território e com as estruturas geométricas pertinentes ao plano, as hierarquias e os elementos de referência do traçado, as praças e seu papel na organização urbana, as estruturas de quarteirões e de loteamento e os processos de planejamento e de construção da cidade (TEIXEIRA, 2012).

No tocante ao processo de configuração territorial, havia dois sistemas bases para efetuar as demarcações de terras de uma colônia. O primeiro chamavase divisão por linhas demarcatórias previamente traçadas e picadas e o segundo adotava um critério mais racional levando-se em conta a topografia do terreno. No primeiro método as demarcações eram feitas de maneira rígida e ortogonal, levando em consideração o sentido norte-sul e leste-oeste com uma linha previamente traçada. Após a delimitação do número de lotes e as suas dimensões, traçavamse os limites da colônia, constituídos de formas retangulares grandes, simétricos e do mesmo tamanho (Figura 3). Essa tipologia de demarcação não levava em conta a topografia do terreno e os lotes tinham tamanhos diversos, variando de 48 a 77 hectares. Esse tipo de demarcação predominou nas chamadas "colônias velhas" encontradas no nordeste do Rio Grande do Sul (LASALVIA; HANDSCHUNCH, 1974).

Para agilizar o processo de colonização, no dia 28 de outubro de 1848 as províncias nacionais receberam do Império 36 léguas quadradas de terras de- 


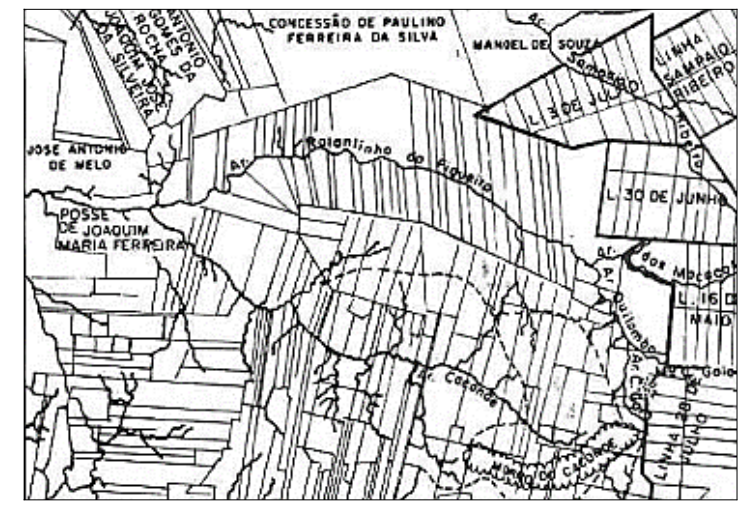

Figura 3: Traçado típico de colonização em terras sul riograndenses. Fonte: LASALVIA; HANDSCHUNCH, 1974 p. 27.

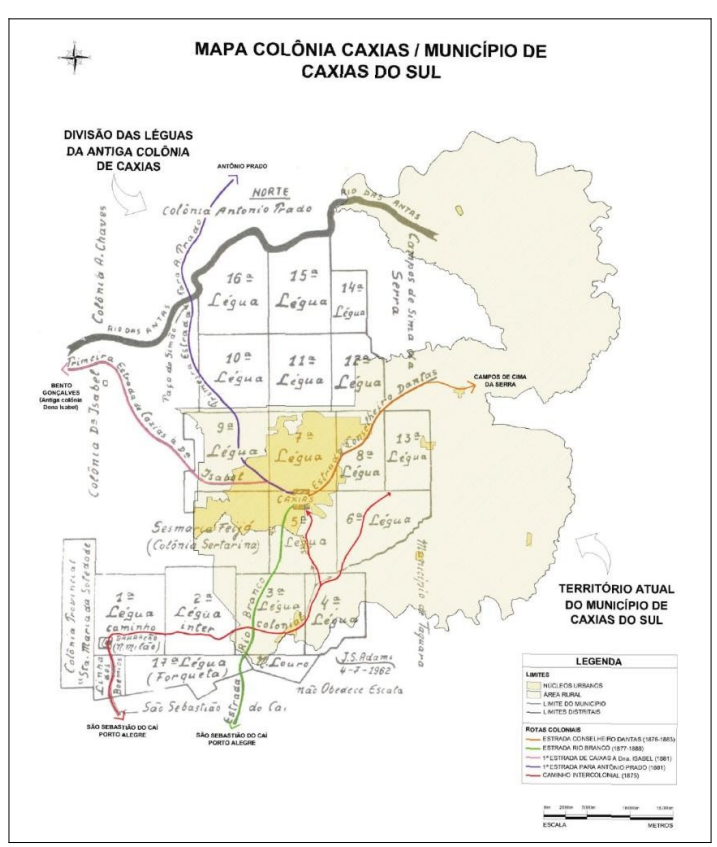

Figura 4: Mapa com as divisões territoriais em léguas da Colônia de Caxias. Fonte: Arquivo Histórico Municipal João Spadari Adami. volutas com o objetivo de colonizar. Mesmo com dificuldades de prosperar economicamente as colônias foram desenvolvendo-se e aumentando seu número populacional. Ao mesmo tempo em que se recuava a floresta para a criação de lotes, esses últimos eram automaticamente valorizados e como consequência aumentava-se a procura por espaços vazios para a locação de colônias agrícolas. Com o sucesso da primeira fase da colonização deu-se início a segunda fase, ou também chamado colonização Provincial. Durante esse período as colônias fundadas pelo Império receberam incentivos econômicos do Estado, já que ele foi responsável pelo surgimento de novos núcleos urbanos (GIRON; HERÉDIA, 2007).

As implantações das colônias no Rio Grande do Sul aconteceram graças à interlocução de diferentes fatores históricos que permitiram a configuração do espaço.

Vale ressaltar que as colônias particulares também ganharam destaque no período Imperial, pois contribuíram para a expansão populacional do território sul rio-grandense. Essas colônias desenvolveram-se em terras até então não ocupadas e próximos ao Vale do Caí, Taquari e Rio Pardo, por exemplo (ROCHE, 1969).

\section{Entre linhas: a colônia e a sede de Caxias/RS}

Para Stormowski (2005) a Colônia de Caxias foi fundada em 1874 e em 1870 haviam sido fundadas as colônias Conde d'Eu (atual município de Garibaldi) e Dona Isabel (Bento Gonçalves). Porém, antes de 1875 existiam poucas famílias estabelecidas nessas colônias, formadas particularmente por imigrantes alemães. A aproximação de Caxias das ex-colônias alemãs, principalmente do município de São Sebastião do Caí, desmembrado de São Leopoldo, Ihe permitiu inserir-se em um mercado regional, já anteriormente estruturado.

A Colônia de Caxias teve sua fundação no ano de 1875. Num primeiro momento foi denominada pelas autoridades como "Fundo de Nova Palmira". Os responsáveis pela administração da recém-criada colônia integravam a Comissão de Terras do Império e delimitaram a divisão do território em 17 léguas, divididas em travessões e lotes. Os travessões demarcavam a frente e o fundo de cada lote. Em média havia 32 lotes em cada travessão (Figura 4). Em grande parte os lotes não ultrapassavam os 35 hectares (COSTA; GARDELIN, 1993).

Quando iniciou a imigração italiana estava, de certa forma, concluída a medição das terras localizadas mais ao sul, contemplando o núcleo Louro, Forqueta, além das $1^{\mathrm{a}}$ e $2^{\mathrm{a}}$ léguas - que perfaziam um território de pouco mais de 3 léguas então denomina 
do de "Colônia a Fundos de Nova Palmira". A colônia também era conhecida como "Campo dos Bugres", uma referência a uma clareira existente na mata onde estava localizado um cemitério indígena, local que viria a se estabelecer a Sede Dante, sua sede administrativa e principal área urbana. No ano de 1877 essa colônia passa a denominar-se Caxias, mudando para Caxias do Sul apenas em 1910 (STORMOWSKI, 2005).

A pesquisadora Marcia S. Stormowski (2005) esclarece que é muito comum encontrar na bibliografia a afirmação de que a área da Colônia de Caxias era de 16 ou 17 léguas quadradas, dependendo se está incluída Forqueta e o núcleo Louro ou apenas os quadriláteros demarcados até o início dos anos de 1880. Conquanto, algumas das léguas não chegavam a medir uma légua quadrada, enquanto outras mediam mais do que isso. Assim, a área de 16 "Léguas" não era de 16 léguas quadradas, mas de pouco mais de 14 léguas quadradas; computando também o núcleo Louro e Forqueta, a área inicial da referida colônia era de cerca de 15 léguas quadradas.

Entre os anos de 1880 e 1884 foram demarcadas ainda algumas áreas periféricas às léguas iniciais, próximas aos rios da região, particularmente ao rio das Antas, mas também ao arroio Piahy e ao rio São Marcos. Com essa expansão das medições, a Colônia de Caxias prolongava-se até o limite com os rios. Desse modo, a área de pouco mais de 15 léguas quadradas formada pelas 16 "Léguas" e pelos núcleos de Louro e Forqueta, somada às quase 4 léguas de área da extensão da Colônia, resulta na área total da Colônia de Caxias de quase 19 léguas quadradas, ou seja, cerca de 82.764 hectares (STORMOWSKI, 2005).

A Colônia de Caxias foi estruturada em 19 léguas, entretanto, a sede da Colônia foi idealizada na primeira légua, que ficou conhecida como Nova Milano. O local era o mais apropriado, já que os imigrantes que partiam da Itália para povoar o território da colônia passavam pela primeira légua, o que facilitava o acesso e a distribuição deles. Mais tarde, Luis Antônio Feijó Júnior, proprietário de alguns lotes na primeira légua, sugeriu a transferência da sede para a quinta légua, então denominada como Campo dos Bugres. Luis Antônio Feijó Jr. alegou que, no sentido geográfico, a transferência da colônia melhoraria a logística e estaria melhor posicionada para cuidar das outras léguas (NASCIMENTO; CAMPO, 2009).

Destacados homens da sociedade local incumbiram o engenheiro Augusto Francisco Gonçalves, em meados de 1876, da responsabilidade de traçar o espaço urbano da Sede da colônia. A área destinada ao traçado urbano foi a $5^{\text {a }}$ légua, formada por dois travessões. Ela permitiu a divisão em três lotes iguais. Conquanto, os colonos residentes na Sede 


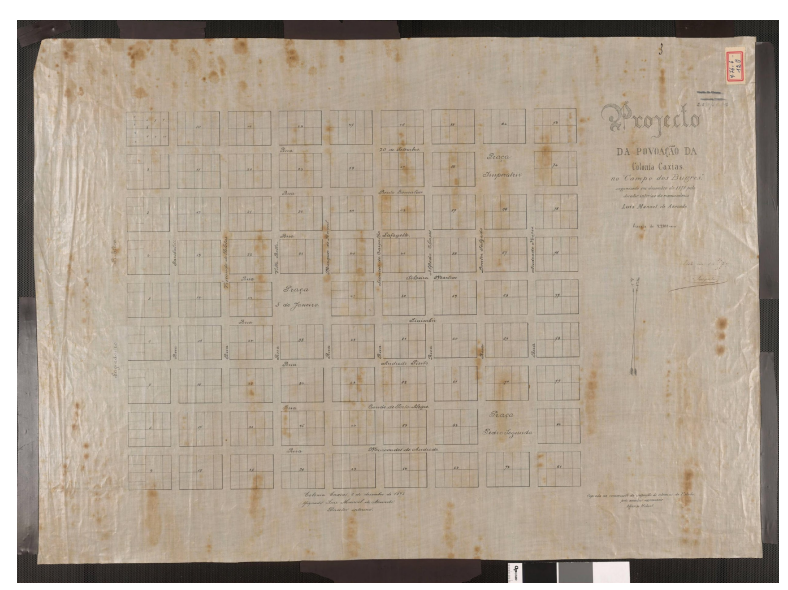

Figura 5: Projecto da Povoação da Colônia de Caxias 1978.

Fonte: Arquivo Histórico Municipal João Spadari Adami não respeitaram o zoneamento proposto e construíram suas casas em desalinho aos eixos viários previamente propostos (NASCIMENTO; CAMPO, 2009).

O primeiro desenho do núcleo urbano foi aprovado em 10 de janeiro de 1878, pelo então presidente da província Marcondes de Andrade, autorizando também a construção da primeira igreja e escola (Figura 5). Os primeiros moradores foram Felice Laner, Luigi di Canali, Giovanni Paternoster e outros. Como o principal objetivo estava diretamente ligado à questão da agricultura, percebe-se a falta de cuidado com o terreno, com a topografia, com as questões hídricas, ocasionando dificuldades de assentamento e bem-estar, especialmente durante o período do inverno (MACHADO, 2001).

Foi Luiz Manoel de Azevedo o responsável pela organização final da planta em tabuleiro de xadrez, conformando nove quarteirões por nove quarteirões, sendo oito ruas no sentido leste-oeste e oito ruas no sentido norte-sul. $O$ projeto ainda previa a construção de três praças. A mais central recebeu o nome de Praça 05 de Janeiro, a segunda, mais a norte, recebeu o nome de Praça Imperatriz e a última, localizada mais ao sul, foi denominada como Praça Pedro II. Outro dado importante que merece ser destacado são os desenhos das quadras. A tipologia urbana se estrutura na forma retangular, onde cada quadra é composta por dez lotes. Con- forme nossas análises, os lotes deveriam possuir aproximadamente $20,00 \mathrm{~m}$ de frente por $40,00 \mathrm{~m}$ de fundos, o que significa que a área total de cada um desses lotes era de $800 \mathrm{~m}^{2}$.

Nascimento (2009) explica que para chegar ao resultado final do traçado urbano da sede da colônia de Caxias contou-se com a atuação de outros engenheiros. Além do engenheiro Augusto Francisco Gonçalves, a comissão de demarcação de terras era formada por outros engenheiros, cabendo a Luiz Manuel a organização final do traçado da sede.

A questão da realocação dos moradores aconteceu em um sistema ordenado, onde cada indivíduo recebeu um lote na mesma proporção e próximo à localidade antiga. Um exemplo de construções que tiveram que ser realocadas é a do Senhor Antônio Lesso que construiu sua residência no Lote 6 da Quadra 31 e mais tarde o lote foi destinado a receber um edifício governamental, fazendo com que 0 imigrante fosse deslocado para um outro lote (NASCIMENTO; CAMPO, 2009).

Quanto aos lotes agrícolas, suas dimensões variavam em aproximadamente 25 hectares, podendo chegar até 50 hectares. As áreas eram consideradas simétricas e a demarcação ocorria sempre perpendicularmente à linha demarcatória, indicando um sentido organizacional. Os padrões do traçado da Sede da Colônia de Caxias seguiam o modelo retangular, podendo variar em quadriculares e/ou re- 


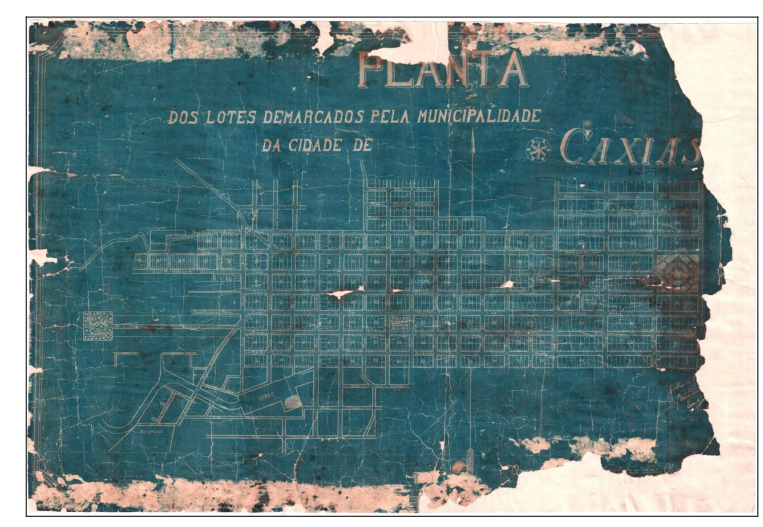

Figura 6: Planta geral do município de Caxias, 1926 Fonte: Arquivo Histórico Municipal João Spadari Adami

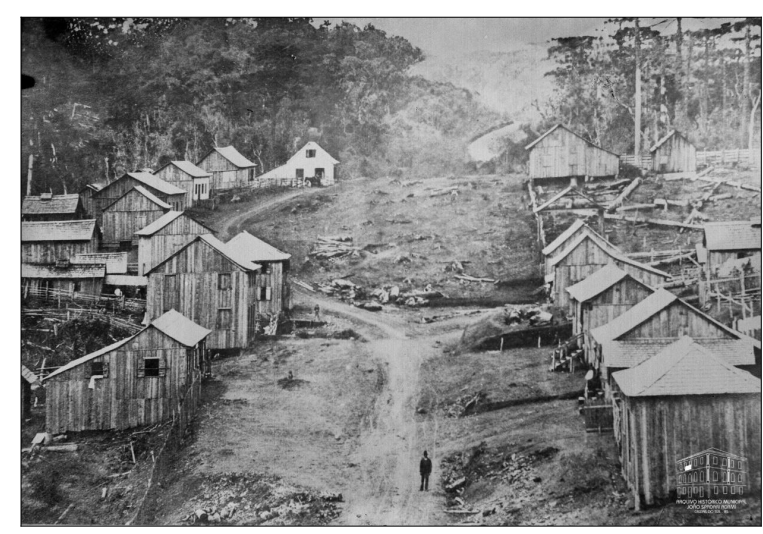

Figura 7: Vista parcial da antiga Colônia de Caxias, 1880 Fonte: Arquivo Histórico Municipal João Spadari Adami (Coleção Francisco Fortuna).

usjt • arq.urb • número 28 | maio-agosto de 2020 tangulares, sempre divididos por uma linha demarcatória de onde iniciavam os lotes (SALVIA HANDSCHUNCH, 1974) (Figura 6).

A simetria era visível por meio da aglomeração de lotes urbanos retangulares e regulares entre si. Essa tipologia de traçado permitia uma implementação imobiliária mais invasiva, resultando em uma maior lucratividade por meio da venda de lotes urbanos (MACHADO, 2001).

É preciso salientar que a colonização era uma empresa de intuito rural, agrícola, mas da qual faziam parte projetos de urbanização. Assim como aconteceu em outros episódios de colonização na Província de São Pedro do Rio Grande do Sul com açorianos e alemães, as colônias agrícolas ocupadas majoritariamente por italianos viram a fundação de núcleos urbanos, por parte da iniciativa oficial, que tinham como função sediar o comando do empreendimento de colonização (NASCIMENTO, 2009).

O estudioso Lewis Mumford, ao analisar as origens dos traçados urbanos, relata que as cidades desenhadas de forma reticulada, ortogonal, serviam, desde a Grécia, ao intuito de se criarem novas colônias. Ele afirma que o plano padrão em xadrez foi uma parte essencial do processo, visto que o colono levava para seu uso imediato. "O colono tinha pouco tempo para levantar a topografia do terreno ou explorar os recursos de um sítio: simplificando sua ordem espacial, procurava uma distribuição rápida e mais ou menos igual de lotes de construção" (MUMFORD, 1982, p. 213).

Este tipo de traçado, de maneira geral, não se preocupa com questões topográficas ou hidrográficas, tornando-se altamente agressivo ao meio natural. Um dos únicos objetivos, relativamente claros à execução deste tipo de traçado, se dá por meio da confecção de um número maior de lotes a serem comercializados (MUMFORD, 1982). Pode-se contextualizar que esse traçado permite a abertura de vias em todos os sentidos e facilita a inserção de qualquer equipamento. Tomando como pressuposto a ideia de que o território é capaz de aceitar e se adequar a qualquer tipo de inserção sobre ele (SANTOS, 1988).

A ideia do tabuleiro de xadrez como forma urbana pode ser observada na construção da Sede de Caxias. É oportuno ressaltar também que as disposições das casas também seguiam um padrão, sendo sempre alinhadas junto aos travessões e/ou as ruas imprimindo um aspecto de simetria ao lugar. Essa tipologia construtiva e o adensamento de edificações não supriram as necessidades de conforto ambiental, dificultando uma orientação solar e uma ventilação adequada à época (NASCIMENTO, 2009) (Figura 7). 
2. AHM “João Spadari Adami”: Código de Posturas do Município, 1893, p. $01-02$
Uma das primeiras ações do governo municipal depois de implantar a Colônia de Caxias foi promulgar a Lei Orgânica do Município em 1892 e o Código de Posturas em 1893. Esse corpo de legislaturas inspirou-se no Código da então pequena cidade vizinha, São Sebastião do Caí. O Código de Posturas previa algumas diretrizes urbanas a serem seguidas. Em seu artigo $2^{\circ}$ dizia que "os limites urbanos abrangem o logradouro público e as edificações situadas nas colônias adjacentes à "Vila" e com frente à linha limítrofe ou a outras estradas gerais dentro do perímetro determinado pelo logradouro" ${ }^{\prime 2}$. Em seu artigo $4^{\circ}$ ele esclarece que todas as edificações passariam por fiscalização municipal para verificar se realmente a legislação estaria sendo respeitada.

Por meio dessas legislações homologadas para gerir a urbanidade da Sede da ex-colônia de Caxias é possível observar que mesmo com o traçado padronizado e imposto sobre o território, havia uma grande preocupação em manter uma harmonia entre os lotes, as construções e suas tipologias arquitetônicas (MACHADO, 2001).

\section{Conclusão}

Para analisar a forma urbana através do processo de transformação do parcelamento agrícola em urbano, tendo como estudo de caso a Colônia e a Sede de Caxias/RS, partiu-se da necessidade de conceituar forma urbana, território e suas dimensões a fim de estabelecer um entendimento das inflexões teóricas, políticas e sociais que serviram de base para a construção de uma espacialidade em terras sul rio-grandenses.

Pontuou-se a importância exercida pelas ações político-administrativas, com maior influência a Lei de Terras de 1850, desempenhando um papel fundamental e decisivo na formação e na construção de espaços rurais e urbanos, tendo como eixo indutor os diferentes processos migratórios, tanto em âmbito nacional quanto regional.

A configuração da Colônia bem como da Sede de Caxias fazia parte de um processo maior da política nacional, isto é, a alteração do trabalho escravo em trabalho livre. Tal contexto permitiu que o governo Imperial implantasse inúmeras colônias em territórios nacionais. Entretanto, a parte do território nacional que melhor se posicionou frente a essa demanda foi o atual estado do Rio Grande do Sul.

A solução em traçados lineares tanto dos lotes rurais, assim como dos lotes urbanos, era a que meIhor expressava a necessidade para aquele momento, ou seja, o comércio de terras. A malha ortogonal imposta se conformava na melhor expressão do lucro, pois seria fácil de ser traçada e de se saber previamente os lucros que seriam alcançados em razão da facilidade dos cálculos matemáticos. 
O projeto de imigração idealizado pelo governo Imperial teve como pressuposto, em terras do Rio Grande do Sul, a configuração e domínio territorial. Portugal, quando do período colonial, utilizou da urbanização como forma de controle de seus domínios. No período Imperial nacional observa-se uma similar ideia. Na ex-colônia de Caxias, a delimitação de terras, o próprio movimento de imigração, o projeto da sede de Caxias (urbanização) e até mesmo a presença do saber erudito dos engenheiros representam esse ideário, ou seja, eles denotam o esforço do estado nacional em dominar, controlar e delinear o território.

Em relação ao traçado urbano da sede de Caxias, ele se insere no debate da história da urbanização brasileira. $\mathrm{O}$ conhecimento que esses engenheiros obtiveram durante a formação superior permitiu que localidades urbanas fossem traçadas e fundadas.

A evolução de Caxias do Sul foi constante e ao mesmo tempo rápida, pois teve como base o traçado geométrico hipodâmico. Os lotes continuaram em sua forma regular $e$ as ruas perpendicularmente entre elas. Ao longo dos anos Caxias do Sul teve seu território desmembrado em razão da criação dos municípios de Flores da Cunha (1924), que formou Nova Pádua (1992), e São Marcos (1963).

\section{Referências}

BRUM NETO, Helena. OS TERRITÓRIOS DA IMIGRAÇÃO ALEMÃ E ITALIANA DO RIO GRANDE DO SUL. 2012. $331 \mathrm{f}$. Tese (Doutorado) - Curso de Pós-graduação em Geografia, Faculdade de Ciências e Tecnologia de Presidente Prudente da Unesp, Presidente Prudente, 2012.

CHRISTILLINO, Cristiano Luis. Sob a pena presidencial: a Lei de Terras de 1850 no Rio Grande do Sul e a negociação política. Tempo [s.l.], v. 18, n. 32, p.223-245, 2012.

COSTA, Rovílio; GARDELIN, Mário. Colônia de Caxias Origens. Porto Alegre: Edições Est., 1993.

FAORO, Raymundo. Os Donos do Poder: Formação do Patronato Político Brasileiro. 5. ed. São Paulo: Biblioteca Azul, 2012.

FURTADO, Celso. Formação econômica do Brasil. 32. ed. São Paulo: Companhia Editora Nacional, 2005.

GASSEN, Valcir. A Lei de Terras de 1850 e o direito de propriedade. 1994. 236 f. Dissertação (Mestrado) - Curso de Pós-Graduação em Direito, Universidade Federal de Santa Catarina, Florianópolis, 1994. 
GIRON, Loraine Slomp; HERÉDIA, Vania. História da Imigração Italiana no Rio Grande do Sul. Porto Alegre: Est Edições, 2007.

HOLANDA, Frederico Rosa Borges de et al. Forma urbana: que maneiras de compreensão e representação? Revista Brasileira de Estudos Urbanos e Regionais, Rio de Janeiro, n. 3, p.9-18, out. 2000.Disponível em: < https://repositorio.unb.br/handle/10482/12151 >. Acesso em: $21 \mathrm{fev}$. 2019.

MACHADO, Maria Abel. Construindo uma Cidade: História de Caxias do Sul - 1875 - 1950. Caxias do Sul: Maneco, 2001.

MOTTA, Marcia Maria Menendes. Nas fronteiras do poder: Conflito e direito à terra no Brasil do século XIX. Rio de Janeiro: Vício e Leitura, 1998.

MUMFORD, Lewis. A Cidade na História: suas origens, transformações e perspectivas. 4. ed. São Paulo: Martins Fonte, 1998.

NASCIMENTO, Roberto Revelino Fogaça do. Campo dos Bugres-Sede Dante: a formação urbana de Caxias do Sul (1876-1884). 2009. $117 \mathrm{f}$. Dissertação (Mestrado em História) - Pontifícia Universidade Católica do Rio Grande do Sul, Porto Alegre, 2009.
PESAVENTO, Sandra Jatahy. O imigrante na política rio-grandense, In: LANDO, Aldair Marli (org.). RS: Imigração e Colonização. 2.ed. Porto Alegre: Mercado Aberto, 1992.

PICCINATO JUNIOR, Dirceu. A dialética da propriedade privada no Brasil dos Oitocentos. Labor e Engenho. V. 11, n. 3, pp. $335-354$, set. 2017.

RÖHNELT, Luiz Fernando Guimarães. Os teutogaúchos no bairro três vendas - Pelotas RS: Uma abordagem sobre cultura, espaço e lugar. 2012. 131 f. Dissertação (Mestrado) - Curso de Pósgraduação em Geografia, Universidade Federal do Rio Grande, Rio Grande, 2012.

SALVIA, Flavia La; HANDSCHUNCH, Nilbiamater S. B. Processo de colonização no Rio Grande do Sul. Boletim Geográfico do Rio Grande do Sul, Porto Alegre, v. 17, p. 3-39, jan./dez. 1974.

SANTOS, Carlos Nelson F. dos. A Cidade como um Jogo de Cartas. Niterói: Editora Universitária Eduff, 1988.

SILVA, Lígia Osório. Terras Devolutas e Latifúndio: Efeitos da Lei de 1850. Campinas: Editora da Unicamp, 1996. 
STORMOWSKI, Marcia Sanocki. Crescimento econômico e desigualdade social: o caso da excolônia Caxias - 1875-1910. 2005. 185f. Dissertação (Mestrado) - Programa de Pós-Graduação em História, Universidade Federal do Rio Grande do Sul, Porto Alegre, 2005.

TEIXEIRA, Manuel C. A forma da cidade de origem portuguesa. São Paulo: Editora Unesp, 2012. 